\title{
Building a Vision that Drives Success and Transition in a Family Ranch Business
}

\section{By Donald J. Jonovic and Armando Caballero}

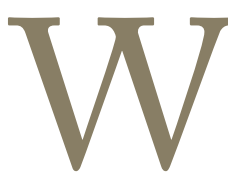

hen asked about their planning process, ranchers often get annoyed. The future is unpredictable. Too much can happen. For many, the concept of long-term planning is a sort of voodoo, crystal-ball gazing of the most selfdelusionary sort. The world changes too fast. There is too little information. And there is too much to do that is much more urgent and important. If ranchers think of planning ownership transition and management succession, it is often because those thoughts are forced on them by legislators and tax laws. Who knew there could be a positive side to taxation? Yet, even if the estate tax laws were abolished, important strategic decisions would still have to be made about what steps to take: 1) to preserve the family culture, 2) to protect and build the value of the ranch, 3) to assure competent management, and 4) to distribute the right assets to the right people, at the right time, in the right way, and in the right form. Tax planning is at least a start, but since it is motivated mostly by the desire to save on taxes, it does little to force ranch owners to address the other key decisions about the future in any real depth. This is why many excellent tax plans can have disastrous effects on business partnerships and families; the planners and the families fail to explore and define concepts like culture, value, competence, and right as they apply uniquely to the family and to the ranch operation involved. In more than 30 years of close relationship with hundreds of family operations, in town and in the country, we have learned that the combination that unlocks the family business future is encoded in three concepts: culture, vision, and investment strategy. No successful planning is possible without focused and persistent effort to decode these three concepts.

\section{Defining Culture Is the First Challenge}

As family businesses grow through the generations, family members become more numerous and have fewer shared experiences. Since one of the main reasons for maintaining a family ranch operation is to help preserve the family, it is critical to understand and adapt to changes in that family.
Any serious discussion of managing or encouraging family unity in a business-owning family requires an understanding of, and careful definition of, culture. Culture needs to be defined and understood both as it currently exists in the context of the family branches, as well as in the context of the business culture and values that stem from the founding generations. Most families who own businesses think culture matters, even though those thoughts are not always specifically defined or expressed. Most, if not all, specialists in family company transition and governance agree on the importance of family culture, the family history, and values as anchors or foundations for success. In the article, "Recognizing and Leveraging Unique Strengths," Dennison writes, "Retaining a connectedness to the past and simultaneously adapting and living the founders' vision is a tremendous and underexploited asset in family firms. Especially in times of economic contraction when market and competitive variables have been fully addressed and optimized, looking inward may be the next most logical place to search for competitive advantage and organizational coherence." 1

Nonetheless, a healthy culture is more dynamic than simply maintaining a connection to the founder and the founder's vision, and it gets harder to maintain as generations proliferate. Not many families in business succeed at this. In their article on multigenerational businesses, Jaffe and Lane write, "A family that succeeds in keeping its fortune unified within a single business or series of shared investments, with multiple family branches sharing control and ownership, is quite rare and the journey is difficult." However, these ideas are important because without understanding the combined family business culture, it is very difficult for owners and stakeholders of a family ranch operation to determine why they want to stay together in business in the first place, let alone what they want for the future.

Family and Business Cultures Interact

Family business specialists often focus on the origins and impacts of culture with respect to the business itself. 
Nevertheless, much of it is applicable to family culture, since, for families in business, the line between the two cultures is about as blurred as the Afghanistan-Pakistan border. This is actually more than a simple overlap. The family culture has a powerful potential to impact business culture. Dennison writes, "Although many corporations are now uttering allegiance to better governance and broader constituencies, the differentiating factor lies in the fact that the behavior of family companies emanates not from external pressure but from a deeply ingrained, learnedat-dinner-table sense of history and morality." In an article written in Family Business Review, Hall et al. looked at that connection explicitly. ${ }^{3}$ They explored the role of cultural patterns in either restricting or encouraging ongoing entrepreneurship in family companies. Ignoring their methodology and research conclusions, there is insight into their theoretical structure by itself (Table 1 ). Not surprisingly, given experience and common sense, the authors conclude that, to encourage robust entrepreneurship in a family firm, a culture that is explicit (values and ideas clearly expressed) and open (encouraging of new and challenging thoughts) is required. Further, they conclude that creation and accumulation of social capital, the ability to keep up with change, to be flexible, to renew, and to grow is essential for the family business that strives to be entrepreneurial.

The family, ideally as many members as possible, must be involved with the ranch's management team in explicitly defining the ranch's culture and values. Both the family and the management team need to remain open and encouraging to the process of examining and adapting that culture. In other words, any family that chooses to own and manage an operating ranch business needs to become conscious of its own culture. They need to be able to define it for everyone to see. They also need to be willing to adapt it for present and future needs. This is easy to say, but how is culture truly defined?

\section{How a Culture Can Be Defined}

We may as well begin with the founder of the organizational culture concept, Edgar Schein. ${ }^{4} \mathrm{He}$ believed that a culture must first have a definable organization in order

Table 1. Three hypothetical dimensions that restrict or encourage family businesses ${ }^{3}$

1. The extent to which the culture is open or closed.

- Openness is defined as accepted and encouraging of new and challenging ideas.

2. The extent to which the culture is explicit or implicit.

- Explicit is defined as clear expression of values and ideas.

3. How richly the culture is connected to family members.

- The more connected members, the richer the culture. to exist. By this, he meant "a number of people interacting with each other for the purpose of accomplishing some goal in their defined environment." 4 When that organization is also a business, the person or persons who creates the organization shapes its culture.

A definable organization is necessary, but not sufficient, however. A culture for Schein does not develop until the organization "... has overcome various crises of growth and survival, and has worked out solutions for coping with its external problems of adaptation and its internal problems of creating a workable set of relationship rules." ${ }^{\prime \prime}$ In other words, culture emerges from going through misery together. Before we begin to define a specific culture, Schein believes, it is important to define its paradigm or cultural essence, by which he means the assumptions members have about underlying truths. As cultures mature, Schein notes, the way challenges have been met over time is taken for granted and, in his words, they drop out of awareness. There are different unconscious assumptions that cause the formation of cultural paradigms in an organization (Table 2).

After comparing the information in Table 2 to known experience, it is relatively easy to see how powerful and potentially disrupting unconscious assumptions can be if they are not shared. Schein focused on business culture, but the implications for defining a family culture are clear. All families have cultures in the anthropological sense, but when that family owns a family ranch business, family and business cultures become intimately entwined. That fuzzy line between the business and family cultures becomes even more blurred when we consider Schein's further discussion of what is meant by organizational culture. He defines organizational culture as "the pattern of basic assumptions that a given group has invented, discovered, or developed in learning to cope with its problems of external adaptation and internal integration, a pattern of assumptions that has worked well enough to be considered valid and, therefore, to be taught to new members as the correct way to perceive, think, and feel in relation to those problems." ${ }^{4}$ Any ranch owner who has worried about finding the best way to bring in the next generation is basically worrying about integrating new members into the ranch's organizational

Table 2. Assumptions that cause the formation of cultural paradigms in an organization ${ }^{4}$

1. The organization's relationship to its environment. - Dominance, harmonizing, submission

2. The nature of reality and truth.

- What is a fact? How is truth determined?

3. The nature of human beings.

- Good, evil, neutral, perfectible

4. The nature of human activity.

- What is right? What is work? Play?

5. The nature of human relationships.

- Cooperative? Competitive? Communal? 
culture. As shown in Table 3, Schein lists sets of challenges that organizations face in this adaptation and integration process.

Understanding the external and internal challenges organizations face when integrating new family members into a ranch's organization culture for a specific family ranch operation defines its culture (Table 3). Schein's conclusion is that "...founders/owners must have sufficient insight into their own culture to make an intelligent transition process possible." Again and clearly, family culture cannot be analyzed as a separate reality from the business culture, and Schein's analysis seems useful in attempting to define a specific family culture. In short, the culture of true interest is actually the family-business culture mix. This is only a small sampling of the vast literature on culture, but this thinking supports three important must dos for familyowned ranching operations: 1) Operations must make the family ranch culture explicit; in other words, they must analyze, define, and disseminate it. 2) They need to ensure that all family members have a full opportunity to understand and embrace the ranches culture. 3) A process must be implemented for monitoring changes in the family or the business and assuring the culture adapts to them in a positive way. A first step could be to develop and propose a set of core values of the family business for discussion and agreement. Further explanation and refinement is required, but once a working definition is in hand, the process of defining a vision can begin.

\section{Why a Vision?}

For a family ranching business, culture serves a role similar to the orchestration of a musical score. It sets the key, the

Table 3. External and internal challenges organizations face when integrating new members into a ranch's organizational culture ${ }^{4}$

1. External adaptation requires reaching consensus on the following:

- Primary task, core mission, and strategy

- Goals, or the concrete reflection of the core mission

- Means to be used in reaching those goals

- Criteria to be used in measuring progress against those goals

- Remedial strategies in the event of failure to reach those goals

2. Achieving internal integration requires the following:

- Common language and conceptual categories

- Group boundaries and criteria for inclusion and exclusion

- Criteria for the allocation of power and status

- Criteria for intimacy, friendship, and love

- Criteria for allocation of rewards and punishments

- Consensus on ideology and religion tempo, the players, their instruments, the melody, and the harmonies. But a score is only marks on paper. It takes a conductor to bring it all together in an effective whole during an actual performance. Similarly, a culture is only potential, like notes on a page. It needs a driving vision to orchestrate a desired outcome. The outcome described by a family's vision for their business is a complex of specific growth expectations, risk-tolerance levels, and return requirements; all are then implemented in the overarching context of the family-business culture.

A strategy or vision is a touchstone, a statement or understanding of what you, your managers, and your fellow owners want the operation to be. It is what you use to guide your decisions and to evaluate opportunities as they arise. While a strategic plan may or may not be practical for many ranches, a vision is essential for all. In the book Smart Growth: Critical Choices for Business Continuity and Prosperity, Poza describes it this way: "A commonly held vision creates alignment among different social groupings, business segments, staff and line functions, branches of the family involved in a family-owned business, different generations, and key individuals and groups who have previously emphasized their differences, their angles, can now join together and jointly create growth to satisfy the mutually experienced structural tension, the pull, that a good vision provides."

While it may seem that a ranch owner has the luxury to think in the long term, they often do not. Why? Well, the truth, as any ranch owner would gladly explain, is that such freedom is an illusion. Family ranches are severely limited in personnel, funds, and management energy. They generally operate on relatively thin margins and are subject to sudden shifts, wild production cycles, intense (but shortlived) brush fires, unexpected reversals, and equally unexpected opportunities. Therefore, ranch operations find it difficult, if not impossible, to spare anybody from the trenches long enough to give any thought to the long-range conduct of the war.

The argument is compelling: what good is a long-range plan, if you get your head blown off in the short-range process? Surviving the lack of a strategic plan is possible. It is done every day, by hundreds of successful ranch operations. Surviving a lack of understanding of who you are or where your operation is trying to go, however, is not. Consider what the absence of a long-range vision, call it purpose if you will, to the transition of ranch ownership and management can mean. Heirs, as potential successors, have little idea what kind of career future the ranch represents. As far as the next generation is concerned, the future will simply look like more of the past and present. We can forgive the heirs if this prospect does not fire the imagination. Also, their spouses, those powerful in-laws, have no concrete manifestation of "The Dream" to reassure them in times of frustration and discouragement. Management, including the boss, the successors, the non-family key 
employees, and even the hapless hourly help, continually and increasingly, are at the mercy of the environment. Who can blame the blind and exhausted for stumbling off the precipice of bad decisions because there was no path or guard rail to guide them? Another problem is that, without a vision, there are no standards for qualifying successor management for the future other than the standards of the past. Without a vision for the ranch future, potential successors will be immersed in management history throughout most of their formative period. Why should anyone be surprised, then, if these new managers turn out to be incapable of handling change and growth?

The absence of a vision also can mean that there is no schedule or deadline for management transition. Without a vision, transition becomes a someday thing, "someday, when they're ready, but not yet. Not yet." Small wonder that the second-best word to describe a successor is "frustrated." Hence, retirement of the present owner(s) is all but impossible. Who could turn their back on all these brushfires, especially when there is nowhere to go and nobody else around who is prepared to fight them? Lastly, when a vision is lacking, outside advice and help have little impact on the ranch and its managers. Advisors and directors tend to ask questions like, "Where can we help you go?" and "What is it you want to do?" Without a vision, these questions really cannot be answered. Current business or financial success, unfortunately, tends to hide all of these symptoms, at least until it's almost too late to reverse them.

A vision steers the ranch. People will, for once, have some idea in what direction they are heading. This can be a great comfort on cold, lonely nights. With a sound vision, the present owner(s) can begin to have trust in the idea that succession is, in fact, possible. They will finally have something to work with other than vague dreams, subliminal frustrations, and inadequate data.

\section{Why an Investment Strategy is Crucial}

In the days when subsistence ranching was the norm in America, most ranches and ranch families operated on the principal of "from each according to ability, to each according to need." There were not a lot of questions about concepts like investment and return. Both were fairly clear. What was being invested was mostly a combination of labor, brains, and time. There was some cash investment in assets, particularly land, but they were not thought about as balance-sheet items. They were there to help the family survive. Very few subsistence ranches exist in developed economies. Successful ranchers today are business people. But businesses are investments, more specifically, investments made in the hope of some kind of return besides food on the table. If this simple assertion is accepted, all the simplicity and straightforwardness of the old subsistence model ends. As shown in Table 4, more than just capital is invested in businesses.
Even more varied are the forms return can take (Table 4). Considering that each of the listed investments and each of the listed returns in Table 4 are real and valid, and that none represent unusual viewpoints, it can be seen how unlikely it is that any two partners will agree 100\% on the relative importance of items. That is why one of the first steps to take is an analysis of the performance of your operation as a financial investment. This provides a good opportunity to spend some quality time with the accountant, going over financial questions related to something other than the income tax. Financial ratios are familiar to ranch owners, but the analysis of them in light of these investment and return questions is often not as familiar. Simply looking at the multi-year ratios in Table 5 can be a great starting point for a discussion among partners. ${ }^{6}$ The central question is, is this really what we expect and want out of this operation and all of our hard work?

The power of the simple process of partners and stakeholders defining what they want for and from their business warrants great respect. Advisors, particularly accountants and financial specialists, are extremely helpful in the process, and good accounting information is essential to the discussion. With valid data and clear-eyed evaluation, the outcome is relatively simple. The investment strategy is a statement by all of the owners of the business to the effect that they, as a group, accomplish the following:

- Establish a specific minimum return on investment.

- Set a specific target return on investment. This is the return that the particular business, in the opinion of the owners, should be generating to keep the investment in that business prudent and attractive. Usually, this is expressed in some form of rolling, multi-year average.

- Plan to grow owner value annually by a specific amount. This is a definition of reinvestment of some specific percentage of earnings.

- Be willing to accept a specific leverage ratio. This is the definition of risk tolerance. It provides the second important hurdle for analyzing new investments or acquisitions.

- Set a specific policy on what portion of earnings will be distributed to shareholders or LLC members. This is particularly crucial for pass-through entities like LLCs

\section{Table 4. Examples of investments and returns of} modern ranches

\begin{tabular}{|c|c|}
\hline Investment & Return \\
\hline $\begin{array}{ll}\text { 1. } & \text { Capital } \\
\text { 2. } & \text { Time } \\
\text { 3. Effort } \\
\text { 4. } \\
\text { 5. } \text { Ieas } \\
\text { 6. } & \text { Heart }\end{array}$ & $\begin{array}{l}\text { 1. Net Income } \\
\text { 2. Growth } \\
\text { 3. Cash } \\
\text { 4. Power } \\
\text { 5. Career } \\
\text { 6. Opportunity } \\
\text { - Future generations } \\
\text { - Loyal employees }\end{array}$ \\
\hline
\end{tabular}


Table 5. Performance indicator ratios (\%) used in the financial analysis of the performance of an operation $^{6}$

\begin{tabular}{|c|c|c|c|c|}
\hline Performance indicator & Year 1 & Year 2 & Year 3 & $\begin{array}{c}\text { Goal } \\
\text { (benchmark) }\end{array}$ \\
\hline $\begin{array}{l}\text { 1. Operating profit margin } \\
\text { (operating profit/gross revenue) } \times 100\end{array}$ & & & & \\
\hline $\begin{array}{l}\text { 2. Return on assets } \\
\text { (net income after tax/total assets) } \times 100\end{array}$ & & & & \\
\hline $\begin{array}{l}\text { 3. Return on equity } \\
\text { (net income after tax/net worth) } \times 100\end{array}$ & & & & \\
\hline $\begin{array}{l}\text { 4. Current ratio } \\
\text { (current assets/current liabilities) } \times 100\end{array}$ & & & & \\
\hline $\begin{array}{l}\text { 5. Debt-to-asset ratio } \\
\text { (total debt/total assets) } \times 100\end{array}$ & & & & \\
\hline $\begin{array}{l}\text { 6. Asset turnover ratio } \\
\text { (gross revenue/total assets) } \times 100\end{array}$ & & & & \\
\hline $\begin{array}{l}\text { 7. Depreciation expense ratio } \\
\text { (depreciation expense/gross revenue) } \times 100\end{array}$ & & & & \\
\hline $\begin{array}{l}\text { 8. Interest expense ratio } \\
\text { (interest expense/gross revenue) } \times 100\end{array}$ & & & & \\
\hline
\end{tabular}

Adapted from Jonovic and Jonovic $2006 .^{6}$

and S-Corporations, and setting a policy forces discussion regarding the alternative of paying cash to owners rather than reinvesting everything.

\section{The Positive Effects of an Investment Strategy}

It should be obvious by now that envisioning the future of a family-owned ranch is not a one-time project. Putting the first coherent investment strategy together will probably involve some significant concentration of effort. Then, once it is in place, management can take actions specifically focused on achieving the goals contained in the strategy. Review of the strategy and management's progress against it should be regular and ongoing. A defined investment strategy, kept flexible and adapted to inevitable change, provides the backbone of annual budgeting and managementperformance evaluation. It is the North Star toward which the compensation plans point. Establishing an investment strategy has a positive impact on capital and operating budgeting, too. Annual budgeting is usually not done by family ranching operations, mostly with the excuse that the future is impossible to predict, so why bother. With an investment strategy in place, prediction is replaced by expectation, and a budget becomes an important and essential tool.
The investment strategy answers that perennial and existential question, "Why are we doing all this?" A dynamic investment strategy will do the following: 1) define the ranch future and the potential career paths for heirs and outside managers; 2) give the spouses of heirs and successors some written, concrete commitment that something will come of their investment of time and emotion; 3) provide real jobs and real performance measures for successormanagers; 4) help define the process of management and ownership transition and, more importantly, provide a basis for deciding the right time for its occurrence; and 5) make it possible for professional advisors and outside directors to help the company survive and grow.

\section{Conclusion}

Family ranches can survive management transition without understanding their culture, having a shared vision, or an investment strategy. But these are few, their transitions do not go as well as they might have, and they may not survive through generations. Planning is difficult and becomes important at all the wrong times, but it is as much an investment in a ranch's future as the investment of funds in the ranch itself. If a ranch-owning family is serious about its 
commitment to the future and future generations, it will focus its efforts in defining a culture, creating a vision, and developing an investment strategy. The family will make this investment not only willingly but gladly.

\section{References}

1. Dennison, D., C. Lief, and J. Ward. 1994. Culture in familyowned enterprises: recognizing and leveraging unique strengths. Family Business Review XVII(1):61-70.

2. Jaffe, D. T., and S. H. Lane. 1994. Sustaining a family dynasty: key issues facing complex multigenerational businessand investment-owning families. Family Business Review XVII(1):81-98.

3. Hall, A., H. L. Melin, and M. Nordevist. 2001. Entrepreneurship as radical change in the family business: exploring the role of cultural patterns. Family Business Review XIV(3): 195-208.

4. Schein, E. 1983. The role of the founder in creating organizational culture. Organizational Dynamics 12(summer):13-28.

5. PozA, E. J. 1989. Smart growth: critical choices for business continuity and prosperity. San Francisco, CA, USA: Jossey-Bass, Inc. $231 \mathrm{p}$.

6. Jonovic, D. J., And P. J. Jonovic. 2006. Ag-Planner/IV: an agreement builder for family agribusinesses. Cleveland, $\mathrm{OH}$, USA: Jamieson Press. 132 p.

Authors are Owner, Family Business Management Services, Cleveland, OH 44120, USA, bjonovic@familybusinessmgt.com (Jonovic); and Graduate Fellow, King Ranch Institute for Ranch Management, Texas AESM University-Kingsville, Kingsville, TX 78363, USA, armando.caballero@students. tamuk.edu (Caballero).

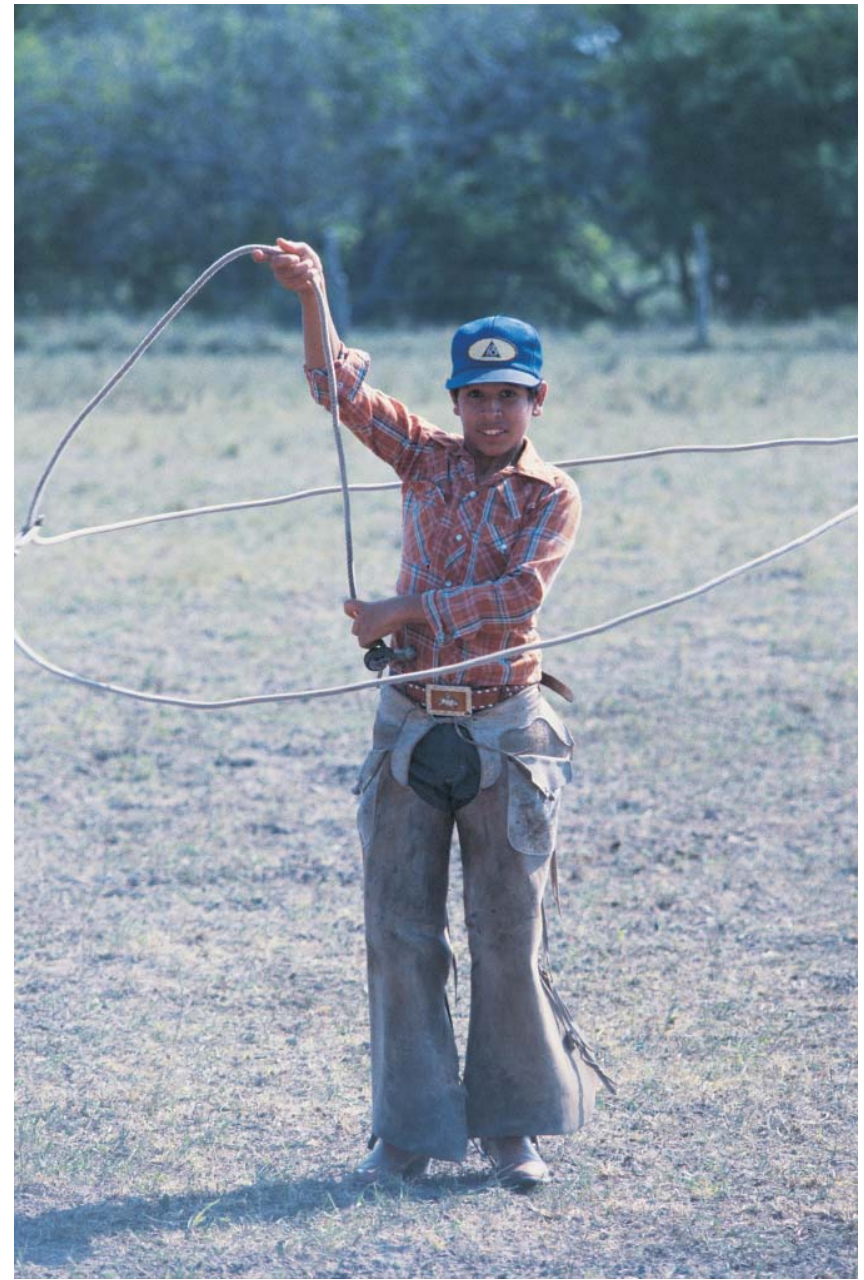

A boy and his rope. Photo by Janell Kleberg. 